\title{
Atributos químicos e estabilidade de agregados sob diferentes culturas de cobertura em Latossolo do cerrado
}

\author{
Glenio G. Santos ${ }^{1}$, Pedro M. da Silveira ${ }^{2}$, Robélio L. Marchão ${ }^{3}$, \\ Fabiano A. Petter ${ }^{4} \&$ Thierry Becquer
}

\begin{abstract}
RESU M O
Objetivou-se, com este trabalho, avaliar o efeito de diferentes culturas de cobertura sobre os atributos químicos e a estabilidade de agregados de um Latossolo do cerrado, sob plantio direto. 0 estudo foi conduzido em área experimental na Embrapa Arroz e Feijão, em Santo Antônio de Goiás, GO. As culturas de cobertura avaliadas foram: braquiária, milho em consórcio com braquiária (integração lavoura-pecuária), guandu anão, milheto, capim mombaça, sorgo granífero, estilosantes e crotalária. As amostras foram coletadas em abril de 2005 e 2006. O delineamento experimental foi o de blocos completos ao acaso com quatro repetições e os tratamentos arranjados em esquema fatorial $8 \times 2$, sendo oito culturas de cobertura e duas profundidades de amostragem do solo: 0-0,10 e 0,10-0,20 m. As culturas de cobertura influenciam, de forma diferenciada, os valores de $\mathrm{pH}$ e os teores de cálcio, magnésio, alumínio, fósforo, potássio, cobre, zinco e ferro do solo. 0 tratamento estilosantes tem maior poder em acidificar o solo. A agregação do solo varia com as culturas de cobertura e com a profundidade.
\end{abstract}

Palavras-chave: gramíneas tropicais, leguminosas, manejo do solo, plantio direto, rotação de culturas

\section{Chemical properties and aggregate stability under different cover crops in cerrado O xisol}

\begin{abstract}
AB STRACT
The objective of this study was to evaluate the effect of different cover crops on chemical properties and aggregate stability in a cerrado 0 xisol under no-tillage. The study was carried out in Embrapa Rice and Beans, in Santo Antônio de Goiás, GO, Brazil. The cover crops evaluated were: Urochloa brizantha, U rochloa brizantha and corn in association (crop-livestock integrated), Cajanus cajan, Pennisetum glaucum, Panicum maximum, Sorghum bicolor, Stylosanthes guianensis and Crotalaria juncea. The soil samples were collected in April and September 2005 and April 2006. The experimental design was in completely randomized blocks with four replications and treatments arranged in factorial scheme $8 \times 2$, eight cover crops and two soil sampling depths, 0-0.10 and 0.10-0.20 m. The different cover crops affect $\mathrm{pH}$ values and calcium, magnesium, aluminum, phosphorus, potassium, copper, zinc and iron contents of the soil. The Stylosanthes guianensis treatment caused more acidification. The soil aggregation varied with cover crops and depths.
\end{abstract}

Key words: tropical grasses, leguminous, soil management, no-tillage, crop rotation

\footnotetext{
${ }^{1}$ U niversidade Federal do Piauí (U FPI), Programa de Pós-G raduação em Solos e Nutrição de Plantas, BR 135, km 03, CEP 64900-000, Bom Jesus, PI, Brasil. Fone/Fax: (89) 3562-2468. E-mail: gleniogm@ufpi.edu.br

2 Embrapa Arroz e Feijão, GO 462, km 12, CEP 75375-000, Santo Antônio de Goiás, GO, Brasil. Fone: (62) 3533-2179. E-mail: pmarques@cnpaf.embrapa.br

${ }^{3}$ Embrapa Cerrados, BR 020, km 18, CEP 73310-970, Planaltina, DF, Brasil. Fone: (61) 3388-9844. E-mail: robelio.leandro@cpac.embrapa.br ${ }^{4}$ U niversidade Federal do Piauí (U FPI), Programa de Pós-Graduação em Fitotecnia, BR 135, km 03, CEP 64900-000, Bom Jesus, PI, Brasil. Fone/ Fax: (89) 3562-1929. E-mail: petter@ufpi.edu.br

${ }^{5}$ Institut de Recherche pour le Développement (IRD), UMR 210 Eco\&Sols 2, place Viala, 34060 Montpellier cedex 2, France. E-mail: thierry.becquer@ird.fr
} 


\section{INTRODUÇÃO}

Os solos dominantes do bioma cerrado, notadamente os Latossolos são, de modo geral, quando não antropizados, de textura argilosa, bem estruturados e com alta estabilidade de agregados, embora altamente intemperizados, ácidos e pobres em nutrientes essenciais para as plantas (Lopes \& Cox, 1977). Em condições antrópicas o manejo inadequado desses solos afeta seu conteúdo de matéria orgânica e sua estrutura, diminuindo a disponibilidade de nutrientes e a agregação e, em consequência, sua porosidade (Santos et al., 2011).

Em geral, o grau de decomposição do material orgânico, proveniente de espécies leguminosas, é mais rápido se comparado ao das gramíneas em virtude da sua menor relação $\mathrm{C} / \mathrm{N}$. Assim, as limitações devidas à fertilidade e capacidade de troca de cátions, tal como a baixa capacidade de retenção de água dos solos do cerrado, podem ser corrigidas ou amenizadas, em parte, pelo incremento nos teores de matéria orgânica, utilizando-se rotação entre diferentes espécies vegetais.

Dentre as tecnologias disponíveis visando ao correto manejo dos solos tropicais, destaca-se o sistema plantio direto (SPD) o qual consiste na implantação da cultura principal sob a palhada de uma cultura de cobertura que tenha sido introduzida em cultivo sequencial ou rotacionado. Atualmente, a maior atenção dada a este sistema se justifica pela constatação dos seus potenciais benefícios agronômicos, econômicos, sociais e ambientais.

Deste modo, a produção de biomassa das culturas de cobertura utilizadas como adubo verde é um aspecto relevante para o SPD, visto que algumas espécies apresentam crescimento vegetativo abundante. Braz et al. (2005) verificaram que as gramíneas braquiária, sorgo, milho e mombaça, foram mais eficientes em produzir fitomassa total quando comparadas com as leguminosas guandu e estilosantes. Entre os principais efeitos das culturas de cobertura sobre a fertilidade do solo, estão: aumento do teor de matéria orgânica, maior disponibilidade de nutrientes, maior capacidade de troca de cátions efetiva do solo, o favorecimento da produção de ácidos orgânicos, diminuição dos teores do alumínio trocável pela sua complexação e incremento da capacidade de reciclagem e mobilização de nutrientes lixiviados ou pouco solúveis que estejam nas camadas mais profundas do perfil do solo (Calegari, 2006).

Quanto à estrutura do solo em SPD o aporte de quantidades elevadas de resíduos vegetais sobre a camada superficial pode contribuir com a presença de agregados estáveis por períodos mais longos. A estabilidade de agregados, a macroporosidade e a condutividade hidráulica podem aumentar rapidamente com a inclusão de gramíneas do gênero Urochloa spp. (Syn. Brachiaria) nos sistemas de produção e/ou rotação de cultivos (Kluthcouski et al., 2004). Isto se deve à combinação de três efeitos principais: ausência de preparo durante o ciclo da pastagem, presença de um denso sistema radicular, que atua como agente agregante e maior atividade da macrofauna do solo em pastagens (Marchão et al., 2007). De acordo com Salton et al. (2008), o aumento da estabilidade de agregados proporciona uma estruturação melhor do solo provendo seu interior com espaços porosos e possibilitando melhor desenvolvimento do sistema radicular das plantas, da fauna do solo e do fluxo de ar e água.

Portanto, a utilização de espécies produtoras de palhada que contribuam para formar agregados estáveis, que mobilizem os nutrientes na camada agricultável, retendo-os na sua fitomassa e os devolvendo ao solo durante a decomposição, é essencial no SPD (Denardin \& Kochhann, 1993). Contudo, há necessidade de se verificar a real contribuição dessas espécies com a finalidade de se manter ou melhorar a estrutura e a fertilidade do solo em áreas sob plantio direto e elevar a produtividade das culturas comerciais (Silveira et al., 2010).

Neste trabalho objetivou-se avaliar o efeito de diferentes culturas de cobertura implantadas durante cinco anos, sobre os atributos químicos e a estabilidade de agregados em Latossolo do cerrado, sob sistema plantio direto.

\section{Material e MÉTOdos}

O estudo foi conduzido na área experimental da Fazenda Capivara, pertencente à Embrapa Arroz e Feijão, no município de Santo Antônio de Goiás, GO (16² 28’ 00”' S e 49 17’ 00”'W), em Latossolo Vermelho Acriférrico típico, textura argilosa, A moderado, fase floresta tropical subcaducifólia e relevo plano (Santos et al., 2010); o clima, conforme classificação de Köppen é Aw, tropical de savana, megatérmico.

O delineamento experimental utilizado foi o de blocos ao acaso com quatro repetições e os tratamentos arranjados em esquema fatorial $8 \times 2$, sendo oito culturas de cobertura e duas profundidades de amostragem: 0-0,10 e 0,10-0,20 m; as culturas avaliadas foram: braquiária (Urochloa brizantha) cv. Marandu; milho (Zea mays L.) - híbrido HT BRS 3150, em consórcio com U. brizantha; milheto (Pennisetum glaucum L. R. Br.) - cv BN - 2; capim mombaça (Panicum maximum) cv. Mombaça; sorgo granífero (Sorghum bicolor L. Moench) - cv BR 304; guandu anão (Cajanus cajan L. Millisp); crotalária (Crotalaria juncea L.) e; estilosantes (Stylosanthes guianensis) cv. Mineirão, cultivadas em cinco anos, sob plantio direto.

O estudo iniciou-se em novembro de 2001 com o plantio direto das diferentes culturas de cobertura, que foram adubadas com $400 \mathrm{~kg} \mathrm{ha}^{-1}$ da fórmula 5-30-15 $\left(\mathrm{N}_{-} \mathrm{P}_{2} \mathrm{O}_{5}-\mathrm{K}_{2} \mathrm{O}\right)$. Este procedimento foi repetido anualmente, até novembro de 2006; em 2005 já tinham sido aplicados, em toda a área experimental, em superfície e sem revolvimento do solo, $4.000 \mathrm{~kg} \mathrm{ha}^{-1} \mathrm{de}$ calcário dolomítico; as culturas de cobertura foram cultivadas na safra de verão cujas parcelas tinham $6 \mathrm{~m}$ de largura por $10 \mathrm{~m}$ de comprimento. Os estilosantes, devido ao seu pequeno crescimento, e o milho consorciado com braquiária, receberam adubação nitrogenada em cobertura de $30 \mathrm{~kg} \mathrm{ha}^{-1}$ utilizandose, como fonte de nitrogênio, o sulfato de amônio.

Todas as culturas de cobertura foram cortadas no mesmo dia, no mês de abril de cada ano, utilizando-se um triturador de palhada e se deixando este material na superfície do solo; antes do corte foram colhidos apenas os grãos de milho e sorgo. Os rendimentos médios anuais de matéria seca da parte aérea das coberturas, foram $11.000 \mathrm{~kg} \mathrm{ha}^{-1}$ (braquiária); $4.300 \mathrm{~kg} \mathrm{ha}^{-1}$ (consorciação do milho com braquiária); $3.600 \mathrm{~kg} \mathrm{ha}^{-1}$ (guandu); 
$6.600 \mathrm{~kg} \mathrm{ha}^{-1}$ (milheto); $8.200 \mathrm{~kg} \mathrm{ha}^{-1}$ (mombaça); $4.600 \mathrm{~kg} \mathrm{ha}^{-1}$ (sorgo); $2.600 \mathrm{~kg} \mathrm{ha}^{-1}$ (estilosantes) e $6.900 \mathrm{~kg} \mathrm{ha}^{-1}$ (crotalária).

As amostragens do solo para as análises químicas e físicas foram realizadas em abril de 2005 e 2006.

Os atributos químicos do solo foram determinados a partir de uma amostra composta de dez amostras simples; o pH foi definido em suspensão aquosa (relação 1:2,5); os alumínio $\left(\mathrm{Al}^{3+}\right)$, cálcio $\left(\mathrm{Ca}^{2+}\right)$ e magnésio $\left(\mathrm{Mg}^{2+}\right)$ trocáveis foram extraídos em $\mathrm{KCl} 1 \mathrm{~mol} \mathrm{~L}^{-1}$; o fósforo $(\mathrm{P})$ e o potássio $\left(\mathrm{K}^{+}\right)$disponíveis, extraídos em solução Mehlich $1\left(0,0125 \mathrm{~mol} \mathrm{~L}^{-1}\right.$ de $\mathrm{H}_{2} \mathrm{SO}_{4}$ e 0,050 mol L $\mathrm{L}^{-1} \mathrm{de} \mathrm{HCl}$ ); micronutrientes, determinados por espectrofotometria de absorção atômica utilizando-se o extrator Mehlich 1. Com vista à determinação da matéria orgânica total do solo (MOS) empregaram-se o método da oxidação por dicromato de potássio e a titulação com sulfato ferroso (método Walkley \& Black). As determinações de todos os atributos químicos do solo foram realizadas de acordo com métodos apresentados em Claessen (1997).

Para a separação entre as classes de agregados determinaram-se as seguintes classes: agregados $>2,0 \mathrm{~mm}$ (AG1); agregados entre 2,0-1,0 mm (AG2); agregados entre 1,0$0,50 \mathrm{~mm}$ (AG3); agregados entre 0,50-0,25 mm (AG4); agregados entre 0,25-0,125 mm (AG5) e agregados < 0,125 mm (AG6); após realizada a separação das classes de agregados calculou-se o diâmetro médio ponderado (DMP, em mm), conforme Claessen (1997).

Os dados obtidos dos atributos químicos e agregados do solo foram submetidos à análise de variância, por meio do programa estatístico SISVAR (Ferreira, 2008) e as médias comparadas pelo teste de Tukey a $5 \%$ de probabilidade. Para o teste de comparação das médias os dados das classes de agregados AG1-AG6 foram transformados para normalizar a distribuição dos dados, aplicando-se a Eq. 1.

$$
\mathrm{Ag}=\operatorname{arcsen}\left(\sqrt{\frac{\mathrm{x}}{100}}\right)
$$

em que:

x - valor da variável a ser transformada

As análises de regressão linear foram estabelecidas utilizando-se o pacote estatístico Statistica 7.0.

\section{RESULTADOS E DISCUSSÃO}

\section{Atributos químicos do solo}

As culturas de cobertura do solo afetaram diferentemente os valores de $\mathrm{pH}$ e os teores dos atributos químicos $\mathrm{Ca}^{2+}$, $\mathrm{Mg}^{2+}, \mathrm{Al}^{3+}, \mathrm{P}, \mathrm{K}^{+}, \mathrm{Cu}, \mathrm{Zn}$ e Fe (Tabela 1 ).

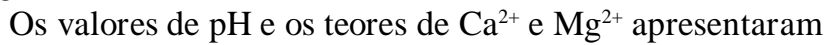
correlação linear positiva com a MOS e a concentração de $\mathrm{Al}^{3+}$ diminuiu com o incremento da MOS, porém, as equações de regressão linear proporcionaram valores de $\mathrm{R}^{2}$ menores que 0,6 , sendo suas respectivas figuras suprimidas deste trabalho, visto que não serviriam para prognósticos futuros. Em solos tropicais, em especial nos Latossolos, com alto grau de intemperização, a carga de superfície dos minerais dominantes (caulinita, óxidos e hidróxidos de ferro e alumínio: solos cauliníticos, oxídicos e gibsíticos) é muito fraca; desta forma, a MOS exerce papel preponderante em razão de contribuir com a elevação da superfície específica, da capacidade de troca de cátions e do incremento de nutrientes nesses solos. Em trabalho através do qual se visou avaliar o efeito de diferentes sistemas de manejo nas relações entre o carbono total e os atributos químicos em Latossolos do cerrado, Siqueira Neto et al. (2009) encontraram valores similares ao deste estudo.

Ao se proceder ao desdobramento dos atributos químicos na camada 0-0,1 m (Tabela 2) em função das diferentes culturas de cobertura do solo avaliadas, observaram-se os maiores valores de $\mathrm{pH}$ nos tratamentos braquiária e milheto, enquanto os tratamentos estilosantes e braquiária consorciada com milho apresentaram os menores valores deste atributo.

De forma inversa aos valores encontrados para o $\mathrm{pH}$, as maiores concentrações de $\mathrm{Al}^{3+}$ foram constatadas nas áreas sob estilosantes e braquiária consorciada com milho e os menores teores deste elemento químico foram observados nas áreas sob braquiária e milheto, respectivamente. Da mesma maneira, os tratamentos estilosantes e braquiária consorciada

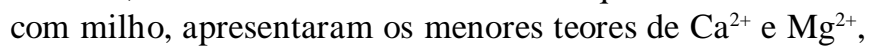
demonstrando ter ocorrido acidificação do solo nesses tratamentos. As mesmas constatações observadas para os atributos $\mathrm{pH}, \mathrm{Ca}^{2+}, \mathrm{Mg}^{2+}$ e $\mathrm{Al}^{3+}$ na camada $0-0,10 \mathrm{~m}$ foram verificadas na camada $0,10-0,20 \mathrm{~m}$, dentro dos mesmos tratamentos. Noble et al. (2002) constataram, estudando o cultivo de diferentes leguminosas, que áreas manejadas sob

Tabela 1. Valores de $\mathrm{pH}$ e teores de $\mathrm{Ca}^{2+}, \mathrm{Mg}^{2+}, \mathrm{Al}^{3+}, \mathrm{P}, \mathrm{K}^{+}, \mathrm{Cu}, \mathrm{Zn}, \mathrm{Fe}, \mathrm{Mn}$ e matéria orgânica do solo (MO S) sob diferentes culturas de cobertura na camada de $0-0,20 \mathrm{~m}^{*}$

\begin{tabular}{|c|c|c|c|c|c|c|c|c|c|c|c|}
\hline \multirow{3}{*}{ Tratamentos } & \multicolumn{11}{|c|}{ Atributos químicos do solo } \\
\hline & \multirow{2}{*}{$\underset{\text { (água) }}{\mathrm{pH}}$} & $\mathrm{Ca}^{2+}$ & $\mathrm{Mg}^{2+}$ & $\mathbf{A l}^{3^{3+}}$ & $\mathbf{P}$ & $\mathbf{K}^{+}$ & $\mathrm{Cu}$ & $\mathrm{Zn}$ & $\mathrm{Fe}$ & $M n$ & \multirow{2}{*}{$\underset{\left(\mathrm{g} \mathrm{dm}^{-3}\right)}{\operatorname{MOS}}$} \\
\hline & & \multicolumn{3}{|c|}{$\left(\mathrm{cmol}_{\mathrm{c}} \mathrm{dm}^{-3}\right)$} & \multicolumn{6}{|c|}{$\left(\mathrm{mg} \mathrm{dm}^{-3}\right)$} & \\
\hline Braquiária & $6,02 a$ & $1,95 a b$ & $0,82 a b$ & $0,05 b c$ & $25 b$ & $106 a$ & $1,74 \mathrm{~b}$ & $7,9 a b$ & $33 a b$ & $8,8 \mathrm{a}$ & $18,6 \mathrm{a}$ \\
\hline Braquiária + milho & $5,75 b c$ & $1,72 \mathrm{~b}$ & 0,56 ef & $0,12 a b$ & $33 a b$ & $88 a b c$ & $2,21 \mathrm{a}$ & $9,4 a$ & $31 \mathrm{ab}$ & $9,3 a$ & $18,2 \mathrm{a}$ \\
\hline Milheto & $5,99 a b$ & $2,08 a b$ & $0,78 b c$ & $0,04 \mathrm{c}$ & $46 a$ & $107 a$ & $1,73 \mathrm{~b}$ & $8,7 a b$ & $35 a$ & $8,9 a$ & $18,1 \mathrm{a}$ \\
\hline Mombaça & $5,89 a b c$ & $1,94 a b$ & $0,89 a$ & $0,07 a b c$ & $29 a b$ & $95 a b$ & $1,65 \mathrm{~b}$ & $8,5 a b$ & $30 a b$ & $9,8 \mathrm{a}$ & 18,3 a \\
\hline Sorgo & $5,92 a b c$ & $1,97 a b$ & $0,63 \mathrm{de}$ & $0,06 \mathrm{bc}$ & $38 a b$ & $71 b c$ & $1,89 a b$ & $8,7 a b$ & $30 a b$ & $9,8 \mathrm{a}$ & $18,8 \mathrm{a}$ \\
\hline Guandu & $5,81 \mathrm{abc}$ & $2,02 a b$ & 0,62 ef & $0,08 a b c$ & $46 a$ & $67 b c$ & $1,77 \mathrm{~b}$ & 9,7 a & $32 a b$ & $9,1 \mathrm{a}$ & 18,6 a \\
\hline Crotalária & $5,88 a b c$ & $2,20 a$ & $0,72 \mathrm{~cd}$ & 0,06 bc & $28 \mathrm{~b}$ & 72 bc & $1,56 \mathrm{~b}$ & $7,5 \mathrm{~b}$ & $29 \mathrm{~b}$ & $8,3 a$ & $18,2 \mathrm{a}$ \\
\hline Estilosantes & $5,68 \mathrm{c}$ & $1,68 \mathrm{~b}$ & $0,53 \mathrm{f}$ & 0,13 a & $34 a b$ & $64 c$ & $1,73 \mathrm{~b}$ & $8,3 a b$ & $29 \mathrm{~b}$ & $8,0 \mathrm{a}$ & $18,4 \mathrm{a}$ \\
\hline $\mathrm{CV}^{* *}(\%)$ & 4,06 & 19,72 & 12,89 & 90,07 & 45,03 & 32,99 & 19,30 & 19,59 & 16,29 & 21,58 & 6,42 \\
\hline
\end{tabular}

* Médias de duas avaliações. Médias seguidas da mesma letra na coluna não diferem entre si pelo teste de Tukey a 0,05 de probabilidade $(p \leq 0,05)$

${ }^{* *} \mathrm{CV}$ - coeficiente de variação 
Tabela 2. Valores dos desdobramentos de $\mathrm{pH}$ e teores de $\mathrm{Ca}^{2+}, \mathrm{M} \mathrm{g}^{2+}, \mathrm{Al}^{3+}, \mathrm{P}, \mathrm{K}+, \mathrm{Cu}, \mathrm{Zn}, \mathrm{Fe}, \mathrm{Mn}$ e matéria orgânica do solo (MOS) sob diferentes culturas de cobertura nas camadas de 0-0,1 e 0,1-0,2 $\mathrm{m}^{*}$

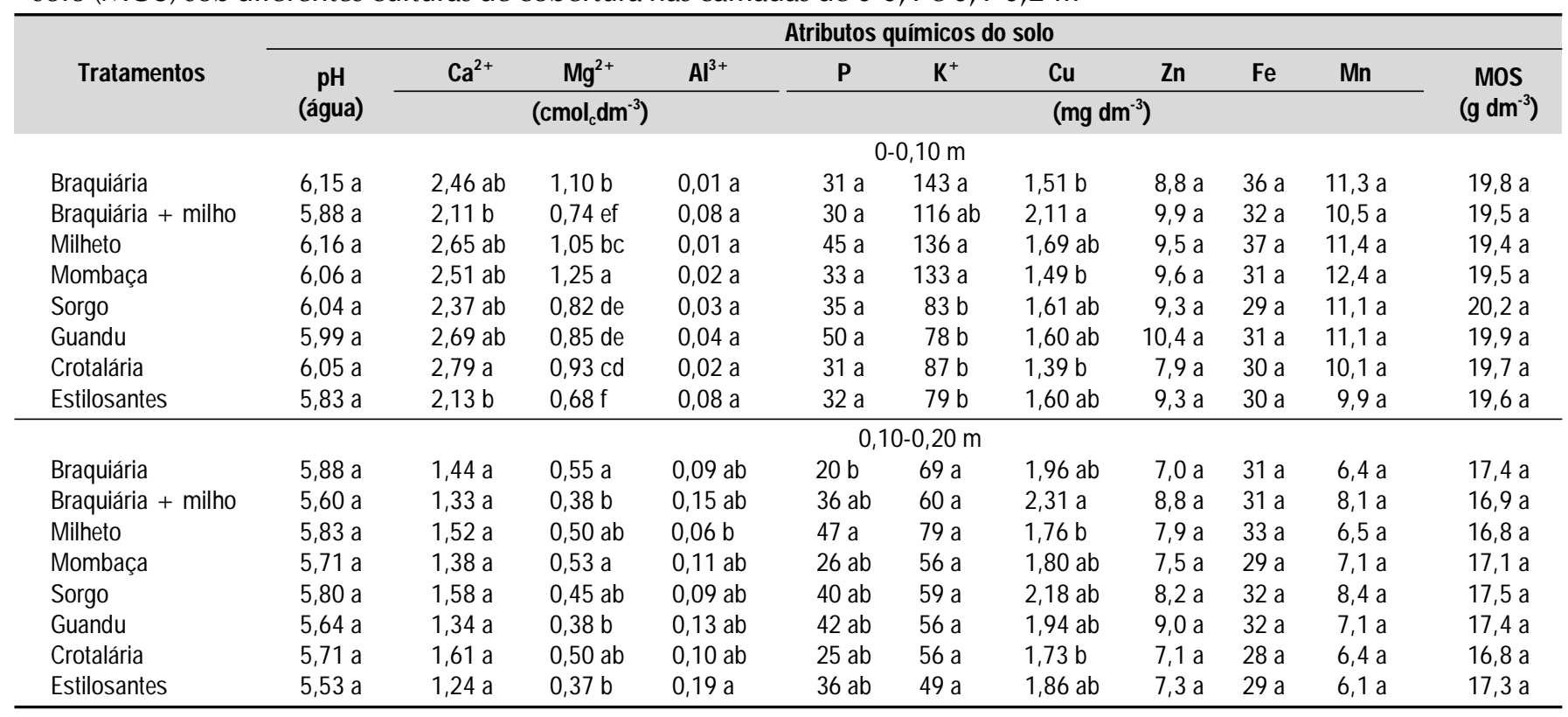

Médias de duas avaliações. Médias seguidas da mesma letra na coluna não diferem entre si pelo teste de Tukey a 0,05 de probabilidade $(p \leq 0,05)$

estilosantes induziram a acidificação do solo. De acordo com Silveira et al. (2010) as aplicações de ureia e sulfato de amônio também podem contribuir para a acidificação de áreas cultivadas visto que fertilizantes amídicos e amoniacais têm a propriedade acidificante do solo, pois no processo de nitrificação ocorre liberação de íons $\mathrm{H}^{+}$(Blanco et al., 2008).

$\mathrm{O}$ elemento $\mathrm{P}$ não apresentou variação significativa na camada superficial do solo, porém, na camada $0,10-0,20$ m houve efeito das diferentes culturas de cobertura sobre os teores deste elemento, sendo as maiores concentrações observadas nos tratamentos milheto e guandu e a menor concentração notada na área sob braquiária. Corrêa et al. (2004) verificaram, estudando o comportamento do P no solo, movimentação deste elemento em profundidade, com características distintas para cada espécie cultivada (milheto, aveia e sorgo-de-guiné), uma vez que na camada mais profunda $(0,15 \mathrm{~m})$, apenas o milheto proporcionou incremento nos teores de P. Esses autores concluíram que as espécies de cobertura também influenciaram na movimentação do $\mathrm{P}$ em profundidade e que o milheto foi mais eficiente na movimentação descendente do fósforo disponível, corroborando com os dados apresentados na Tabela 2.

Quanto ao $\mathrm{K}^{+}$, os maiores teores foram observados nos tratamentos braquiária e milheto demonstrando, para este estudo, que a braquiária foi mais eficiente em reciclar este nutriente na camada superficial do solo confirmando a alta eficácia da ciclagem de $\mathrm{K}^{+}$pelas gramíneas (Raij et al., 1997). Referidos dados corroboram com os obtidos por Pacheco et al. (2011) que verificaram elevadas taxas de liberação de $\mathrm{K}^{+}$pelas gramíneas. Na camada $0,10-0,20 \mathrm{~m}$ não houve efeito dos diferentes tratamentos sobre este elemento químico.

Dentre os microelementos $\mathrm{Cu}, \mathrm{Zn}, \mathrm{Fe}$ e $\mathrm{Mn}$, apenas o $\mathrm{Cu}$ apresentou efeito significativo nas duas camadas avaliadas; entretanto e de acordo com Raij et al. (1997), os valores apresentados nas Tabelas 1 e 2 podem ser considerados altos, para fins de interpretação agronômica. Conforme Consolini \& Coutinho (2004) a disponibilidade no solo e a absorção de Zn pelas culturas diminuem com o aumento do $\mathrm{pH}$ do solo; no entanto, para este estudo o $\mathrm{Zn}$ não se correlacionou com $\mathrm{pH}$ mas houve, sim, correlação linear e positiva entre $\mathrm{Zn}: \mathrm{Ca}$ e $\mathrm{Zn}: \mathrm{Mg}$, mesmo que com valores de $\mathrm{R}^{2}$ inferiores a 0,6 ; apesar disto, ressalta-se que o $\mathrm{Zn}$ é um dos micronutrientes mais limitantes para o aproveitamento agrícola dos solos do cerrado, conforme salientado por Vendrame et al. (2007).

O Mn apresentou correlação positiva com a MOS (porém a equação de regressão linear proporcionou $\mathrm{R}^{2}$ inferior a 0,6 ) sinalizando que as diferentes culturas de cobertura avaliadas promoveram maior ciclagem deste nutriente no solo; embora de acordo com Kliemann et al. (2003) não existem, ainda, indicativos seguros para a recomendação de $\mathrm{Mn}$ em pastagens no cerrado já que encontraram o valor de $78 \mathrm{mg} \mathrm{dm}^{3}$ como sendo o nível crítico de Mn extraído por Mehlich 1 para $U$. brizantha, valor bem acima do nível crítico de $5 \mathrm{mg} \mathrm{dm}^{-3}$ sugerido por Lopes \& Cox (1977).

$\mathrm{O} \mathrm{pH}$ e os teores de $\mathrm{Ca}^{2+}, \mathrm{Mg}^{2+}, \mathrm{Al}^{3+}, \mathrm{K}^{+}, \mathrm{Cu}, \mathrm{Zn}, \mathrm{Mn}$ e MOS variaram em função das profundidades amostradas; com exceção dos elementos $\mathrm{Al}^{3+} \mathrm{e} \mathrm{Cu}$, os demais atributos químicos apresentaram valores superiores na camada $0-0,10 \mathrm{~m}$ de solo (Tabela 3), resultados esses que podem estar associados ao SPD, em que as culturas de cobertura avaliadas foram cortadas e distribuídas de forma homogênea sobre a superfície do solo, pelo tempo de cinco anos consecutivos. $\mathrm{O}$ aporte da biomassa vegetal sobre a superfície do solo e os fatores climáticos presentes no cerrado, somados aos processos biológicos de decomposição deste material, podem ter favorecido a mineralização desses elementos na camada $0-0,10 \mathrm{~m}$ de solo.

Calegari et al. (2008) observaram, em estudo de longa duração com diferentes culturas de cobertura do solo em semeadura direta, que após 19 anos de avaliação todos os tratamentos envolvendo diferentes rotações aumentaram os estoques de 
Tabela 3. Valores de $\mathrm{pH}$ e teores de $\mathrm{Ca}^{2+}, \mathrm{M} \mathrm{g}^{2+}, \mathrm{Al}^{3+}, \mathrm{P}, \mathrm{K}^{+}, \mathrm{Cu}, \mathrm{Zn}, \mathrm{Fe}, \mathrm{Mn}$ e matéria orgânica do solo (MOS) nas camadas de 0-0,10 e 0,10-0,20 m sob diferentes culturas de cobertura*

\begin{tabular}{|c|c|c|c|c|c|c|c|c|c|c|c|}
\hline \multirow{3}{*}{$\begin{array}{c}\text { Camada } \\
\text { (m) }\end{array}$} & \multicolumn{11}{|c|}{ Atributos químicos do solo } \\
\hline & \multirow{2}{*}{$\begin{array}{c}\text { pH } \\
\text { (água) }\end{array}$} & $\mathrm{Ca}^{2+}$ & $\mathrm{Mg}^{2+}$ & $\mathbf{A l}^{3+}$ & $\mathbf{P}$ & $\mathbf{K}^{+}$ & $\mathrm{Cu}$ & $\mathrm{Zn}$ & $\mathrm{Fe}$ & Mn & \multirow{2}{*}{$\begin{array}{c}\text { MOS } \\
\left(\mathrm{g} \mathrm{dm}^{-3}\right)\end{array}$} \\
\hline & & \multicolumn{3}{|c|}{$\left(\mathrm{cmol}_{\mathrm{c}} \mathrm{dm}^{-3}\right)$} & \multicolumn{6}{|c|}{$\left(\mathrm{mg} \mathrm{dm}^{-3}\right)$} & \\
\hline $0-0,10$ & $6,02 \mathrm{a}$ & $2,46 a$ & $0,93 a$ & $0,04 \mathrm{~b}$ & $36 a$ & $107 \mathrm{a}$ & $1,63 b$ & 9,3 a & $32 a$ & $11,0 \mathrm{a}$ & $19,7 \mathrm{a}$ \\
\hline $0,10-0,20$ & $5,71 b$ & $1,43 b$ & $0,46 b$ & $0,11 a$ & $34 \mathrm{a}$ & $60 \mathrm{~b}$ & $1,94 \mathrm{a}$ & $7,8 \mathrm{~b}$ & $31 \mathrm{a}$ & $7,0 \mathrm{~b}$ & $17,1 \mathrm{~b}$ \\
\hline
\end{tabular}

"Médias de duas avaliações. Médias seguidas da mesma letra na coluna não diferem entre si pelo teste de Tukey a 0,05 de probabilidade ( $p \leq 0,05)$

carbono do solo, quando comparados com os da área sob pousio e concluíram, ainda, que o manejo contínuo sob SPD combinado com o uso de culturas de cobertura de inverno resultou em maior quantidade de MOS na superfície do solo, sendo o único tratamento cultivado que se aproximou das condições de floresta não antropizada.

Falleiro et al. (2003) encontraram maiores valores de $\mathrm{pH} \mathrm{em}$ semeadura direta na camada superficial do solo decrescendo com a profundidade amostrada e atribuíram esses resultados às características tamponantes da matéria orgânica e/ou ao aumento da força iônica da solução do solo, devido ao incremento dos teores de $\mathrm{Ca}^{2+}, \mathrm{Mg}^{2+}$ e $\mathrm{K}^{+}$nesta camada de solo. Esses autores também verificaram que o $\mathrm{Al}^{3+}$ apresentou os menores valores na camada superficial da semeadura direta, também resultante do incremento da força iônica da solução do solo e do aumento dos valores de $\mathrm{pH}$ e MOS nesta camada,

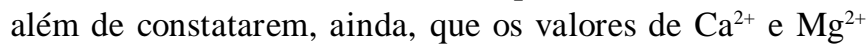
foram maiores na camada superficial do tratamento semeadura direta e afirmarem que este resultado foi devido ao nãorevolvimento do solo e à ciclagem dos nutrientes pelas culturas, conferindo com os resultados obtidos pelo presente trabalho.

$\mathrm{O}$ elemento químico $\mathrm{K}^{+}$apresentou maior concentração na camada superficial do solo. Cavalcante et al. (2007) observaram, estudando a variabilidade espacial de atributos químicos sob diferentes usos e manejos, acúmulo de $\mathrm{K}^{+}$na camada superficial, atribuindo tal resultado também ao não-revolvimento do solo pelo SPD, que favoreceu o acúmulo deste nutriente na camada.

\section{Estabilidade de agregados do solo e diâmetro médio ponde- rado(DMP)}

A avaliação da estabilidade de agregados do solo mostrou que as classes de agregados AG1, AG2, AG3 e AG4, assim como o DMP, variaram em função das diferentes culturas de cobertura do solo (Tabela 4). De acordo com Moreira et al. (2009), diferentes plantas de cobertura influenciam, de forma diferenciada, as características físicas do solo, como: estabilidade de agregados, diâmetro de poros e densidade do solo.

Assim, para se confirmar as constatações observadas por Moreira et al. (2009) no que diz respeito à agregação do solo, procedeu-se ao desdobramento das diferentes classes de agregados e DMP, em função das culturas de cobertura e camadas de solo avaliadas (Tabela 5). Para a camada 0-0,10 m, todas as culturas de cobertura propiciaram maiores valores, tanto na agregação da classe AG1 quanto do DMP, quando comparados com os da camada 0,10-0,20 m. Entre as oito diferentes culturas de cobertura avaliadas verifica-se na camada superficial do solo, que as gramíneas foram mais eficientes em formar agregados estáveis maiores que $2 \mathrm{~mm}$ de diâmetro em comparação as leguminosas, mesmo que tal constatação não se tenha sido confirmada na camada $0,10-0,20 \mathrm{~m}$.

O tratamento braquiária foi o que apresentou maior estabilidade de agregados da classe AG1 e DMP na camada superficial do solo. Por outro lado, os menores valores desses atributos foram observados na área cultivada com crotalária. Assim, pode-se inferir que a elevada porcentagem de agregados maiores que 2 mm de diâmetro (AG1) e DMP observados na área sob braquiária estão associados à presença do sistema radicular abundante e agressivo desta gramínea e à exsudação de compostos orgânicos por suas raízes que, possivelmente, devem ter contribuído para a formação de agregados mais estáveis. Portanto, parece estar evidente a importância do sistema radicular das gramíneas no processo de agregação das partículas do solo.

Tabela 4. D istribuição das classes de agregados do solo sob diferentes culturas de coberturas na camada de $0-0,20 \mathrm{~m}^{*}$

\begin{tabular}{lccccccc}
\hline \multirow{2}{*}{ Tratamentos } & \multicolumn{9}{c}{ Porcentagem (\%) de agregados do solo*** $^{* *}$} & \multicolumn{1}{c}{ DMP } \\
(mm)
\end{tabular}

*Médias de duas avaliações. AG1 - agregados > $2,0 \mathrm{~mm}$, AG2 - agregados entre 1,0-2,0 mm, AG3 - agregados entre 0,5-1,0 mm, AG4 - agregados entre 0,25-0,5 mm, AG5 - agregados entre 0,125-

$0,25 \mathrm{~mm}, \mathrm{AG}$ - agregados < 0,125 mm, DMP - diâmetro médio ponderado; para o teste de comparação de médias, as classes de agregados AG1-AG6 foram transformadas: Eq. (1)

${ }^{* *} \mathrm{CV}$ - coeficiente de variação

${ }^{* * *}$ Médias seguidas da mesma letra na coluna não diferem entre si pelo teste de Tukey a 0,05 de probabilidade $(p \leq 0,05)$ 
Tabela 5. D esdobramento da distribuição das classes de agregados do solo sob diferentes culturas de cobertura na camada de $0-0,10$ e $0,10-0,20 \mathrm{~m}^{*}$

\begin{tabular}{lcccccc}
\hline \multirow{2}{*}{ Tratamentos } & \multicolumn{7}{c}{ Porcentagem (\%) de agregados do solo** } & & DMP \\
& AG1 & AG2 & AG3 & AG4 & AG5 & AG6 \\
(mm)
\end{tabular}

*Médias de duas avaliações. AG1 - agregados > 2,0 mm, AG2 - agregados entre 1,0-2,0 mm, AG3 - agregados entre 0,5-1,0 mm, AG4 - agregados entre 0,25-0,5 mm, AG5 - agregados entre 0,125$0,25 \mathrm{~mm}, \mathrm{AG} 6$ - agregados < 0,125 mm, DMP - diâmetro médio ponderado; para o teste de comparação de médias, as classes de agregados AG1-AG6 foram transformadas: Eq. (1)

** Médias seguidas a mesma letra na coluna não diferem entre si pelo teste de Tukey a 0,05 de probabilidade $(p \leq 0,05)$

Silva \& Mielniczuk (1997) afirmaram que os efeitos benéficos das gramíneas na formação e estabilização dos agregados do solo são devidos à alta densidade de raízes, que promove a aproximação das partículas do solo pela constante absorção de água do perfil do solo. Esses autores ainda relataram que a renovação periódica do sistema radicular das gramíneas e a distribuição uniforme de exsudados no solo estimulam a atividade microbiana cujos subprodutos atuam como agentes cimentantes, contribuindo na formação e estabilização dos agregados, confirmando os resultados obtidos neste estudo.

As classes de agregados AG1, AG2, AG3, AG4, AG5 e DMP variaram em função das camadas amostradas do solo (Tabela 6). A classe de agregados AG1 e o DMP apresentaram maiores valores na camada superficial de $0-0,10 \mathrm{~m}$ de profundidade. Andrade et al. (2009) também constataram que diferentes culturas de cobertura do solo afetaram, de maneira similar, a porcentagem de agregados com diâmetro maior que $2 \mathrm{~mm}$ e o DMP nas duas camadas amostradas $(0-0,10$ e $0,10-0,20 \mathrm{~m})$ indicando que o DMP foi influenciado principalmente por esta fração dos agregados. Desta forma, esses autores concluíram que as culturas de cobertura, especialmente as gramíneas, favoreceram a agregação do solo na camada superficial,

Tabela 6. Distribuição das classes de agregados do solo nas camadas de 0-0,10 e 0,10-0,20 m*

\begin{tabular}{cccccccc}
\hline Camada & \multicolumn{5}{c}{ Porcentagem (\%) de agregados do solo } & DMP \\
\cline { 2 - 7 } (m) & AG1 & AG2 & AG3 & AG4 & AG5 & AG6 & (mm) \\
$0-0,10$ & $73 \mathrm{a}$ & $6,4 \mathrm{~b}$ & $7,2 \mathrm{~b}$ & $4,7 \mathrm{~b}$ & $2,6 \mathrm{~b}$ & $5,7 \mathrm{a}$ & $3,8 \mathrm{a}$ \\
$0,10-0,20$ & $60 \mathrm{~b}$ & $9,7 \mathrm{a}$ & $12,5 \mathrm{a}$ & $7,1 \mathrm{a}$ & $3,8 \mathrm{a}$ & $7,0 \mathrm{a}$ & $3,3 \mathrm{~b}$ \\
\hline
\end{tabular}

"Médias de duas avaliações. AG1 - agregados > 2,0 mm, AG2 - agregados entre 1,0-2,0 mm, AG3 - agregados entre 0,5-1,0 mm, AG4 - agregados entre 0,25-0,5 mm, AG5 - agregados entre 0,125$0,25 \mathrm{~mm}$, AG6 - agregados < $0,125 \mathrm{~mm}$, DMP - diâmetro médio ponderado; para 0 teste de comparação de médias, as classes de agregados AG1-AG6 foram transformadas: Eq. (1)

** Médias seguidas da mesma letra na coluna não diferem entre si pelo teste de Tukey a 0,05 de probabilidade $(p \leq 0,05)$ mantendo-a ou a aumentando em relação à apresentada pelo solo sob vegetação nativa.

Ainda para as camadas de solo estudadas verifica-se haver correlação linear positiva (porém com $\mathrm{R}^{2}<0,6$ ) entre o DMP e MOS. Este resultado indica que o aporte de material orgânico na superfície do solo por meio do SPD, associado ao desenvolvimento do sistema radicular das diferentes culturas de cobertura pode ter contribuído para a elevação na estabilidade dos agregados de maior diâmetro melhorando a qualidade estrutural do solo das áreas avaliadas. Resultados semelhantes foram observados por Oliveira et al. (2010).

De acordo com Portela et al. (2010) em investigações sobre a restauração da qualidade física do solo sob diferentes culturas implantadas em SPD, todas as sequências culturais analisadas foram eficazes em restituir a estrutura do solo durante o período experimental. Neste estudo os autores constataram que na média das sequências culturais, o teor de MOS na camada $0-0,10 \mathrm{~m}$ foi acrescido em $35 \%$ e o valor de DMP em $202 \%$, em relação aos valores do início da avaliação, quando o solo se encontrava degradado tendo chegado, respectivamente, aos 85 e $75 \%$ dos valores originais de campo nativo. Segundo, ainda, esses autores, a expressiva melhoria na qualidade desses atributos deveu-se ao contínuo aporte de material vegetal ao solo, principalmente por meio das raízes das culturas, conforme também mencionado por Silva \& Mielniczuk (1997), o que atesta os resultados encontrados neste trabalho. Salton et al. (2008) observaram que em áreas sob pastagem permanente e pastagem permanente consorciada com leguminosas o percentual de agregados estáveis entre as classes $>4,76$ e 2,00-4,76 $\mathrm{mm}$ da camada $0-0,10 \mathrm{~m}$ foi superior a todos os demais sistemas estudados, mesmo sob SPD e vegetação nativa, confirmando o potencial das gramíneas forrageiras em melhorar a estrutura do solo. 


\section{CONCLUSÕES}

1. As culturas de cobertura influenciam, de forma diferenciada, os valores de $\mathrm{pH}$ e os teores dos atributos químicos cálcio, magnésio, alumínio trocável, fósforo, potássio, cobre, zinco e ferro do solo e os valores de pH e os teores de cálcio, magnésio, alumínio trocável, potássio, zinco, cobre, ferro e matéria orgânica variam com as camadas do solo.

2. O tratamento estilosantes tem maior poder em acidificar o solo.

3. A braquiária é mais eficiente em reciclar o elemento potássio na camada $0-0,10 \mathrm{~m}$ de solo e entre as diferentes culturas de cobertura as espécies da família gramínea são mais eficientes em formar agregados estáveis maiores que $2 \mathrm{~mm}$ de diâmetro, em comparação com as espécies leguminosas, nesta camada de solo.

4. A agregação varia diferentemente com as culturas de cobertura e com as camadas do solo.

\section{AgRADECIMENTOS}

Ao Conselho Nacional de Desenvolvimento Científico e Tecnológico, à Embrapa Arroz e Feijão, à Universidade Federal de Goiás e ao Institut de Recherche pour le Développement (IRD) pelo apoio logístico e financeiro.

\section{LITERATURA CITADA}

Andrade, R. S.; Stone, L. F.; Silveira, P. M. Culturas de cobertura e qualidade física de um Latossolo em plantio direto. Revista Brasileira de Engenharia Agrícola e Ambiental, v.13, p.411418, 2009.

Blanco, F. F.; Folegatti, M. V.; Henriques Neto, D. Doses de N e K no tomateiro sob estresse salino: I. Concentração de nutrientes no solo e na planta. Revista Brasileira de Engenharia Agrícola e Ambiental, v.12, p.26-33, 2008.

Braz, A. J. B. P.; Kliemann, H. J.; Silveira, P. M. Produção de fitomassa de espécies de cobertura em Latossolo Vermelho Distroférrico. Pesquisa Agropecuária Tropical, v.35, p.5564, 2005.

Calegari, A. Sequestro de carbono, atributos físicos e químicos em diferentes sistemas de manejo em um Latossolo argiloso do Sul do Brasil. Londrina: UEL, 2006. 191p. Tese Doutorado

Calegari, A.; Hargrove, W. L.; Rheinheimer, D. S.; Ralisch, R.; Tessier, D.; Tourdonnet, S.; Guimarães, M. F. Impact of longterm no-tillage and cropping system management on soil organic carbon in an Oxisol: A model for sustainability. Agronomy Journal, v.100, p.1013-1019, 2008.

Cavalcante, E. G. S.; Alves, C. A.; Pereira, G. T.; Souza, Z. M. Variabilidade espacial de MO, P, K e CTC do solo sob diferentes usos e manejos. Ciência Rural, v.37, p.394-400, 2007.

Claessen, M. E. C. (Org.). Manual de métodos de análise de solo. 2.ed. Rio de Janeiro: Embrapa CNPS, 1997. 212p. Documentos, 1
Consolini, F.; Coutinho, E. L. M. Efeito da aplicação de Zn e do $\mathrm{pH}$ do solo na disponibilidade do micronutriente. Acta Scientiarum. Agronomy, v.26, p.7-12, 2004.

Corrêa, J. C.; Mauad, M.; Rosolem, C. A. Fósforo no solo e desenvolvimento de soja influenciados pela adubação fosfatada e cobertura vegetal. Pesquisa Agropecuária Brasileira, v.39, p.1231-1237, 2004.

Denardin, J. E.; Kochhann, R. A. Requisitos para a implantação e a manutenção do sistema plantio direto. In: Plantio direto no Brasil. Passo Fundo: Aldeia Norte, 1993. p.19-27.

Falleiro, R. M.; Souza, C. M.; Silva, C. S. W.; Sediyama, C. S.; Silva, A. A.; Fagundes, J. L. Influência dos sistemas de preparo nas propriedades químicas e físicas do solo. Revista Brasileira de Ciência do Solo, v.27, p.1097-1104, 2003.

Ferreira, D. F. SISVAR: Um programa para análises e ensino de estatística. Revista Científica Symposium, v.6, p.36-41, 2008.

Kliemann, H. J.; Magalhães, R. T.; Oliveira, I. P.; Moraes, M. F. Relações da produção de massa verde de Brachiaria brizantha com os índices de disponibilidade de nutrientes em solos sob o sistema barreirão de manejo. Pesquisa Agropecuária Tropical, v.33, p.49-56, 2003.

Kluthcouski, J.; Aidar, H.; Stone, L. F.; Cobucci, T. Integração lavoura-pecuária e o manejo de plantas daninhas. Piracicaba: Potafós, 2004. 20p. Encarte Técnico, 106

Lopes, A. S.; Cox, F. R. A survey of the fertility status of surface soils under "Cerrado" vegetation in Brazil. Soil Science Society America Journal, v.41, p.742-747, 1977.

Marchão, R. L.; Balbino, L. C.; Silva, E. M.; Santos Júnior, J. D. G.; Sá, M. A. C.; Vilela, L.; Becquer, T. Qualidade física de um Latossolo Vermelho sob sistemas de integração lavourapecuária no cerrado. Pesquisa Agropecuária Brasileira, v.42, p.873-882, 2007.

Moreira, J. A. A.; Aguiar, R. A.; Stone, L. F.; Bernardes, T. G.; Pereira Filho, I. A.; Cruz, J. C. Efeito de diferentes plantas de cobertura do solo sobre alguns atributos do solo em sistema de produção orgânico. Revista Brasileira de Agroecologia, v.4, p.3748-3751, 2009.

Noble, A. D.; Middleton, C.; Nelson, P. N.; Rogers, L. G. Risk mapping of soil acidification under Stylosanthes in northern Australian rangelands. Australian Journal of Soil Research, v.40, p.257-267, 2002.

Oliveira, V. S.; Rolim, M. M.; Vasconcelos, R. F. B.; Pedrosa, E. M. R. Distribuição de agregados e carbono orgânico em um Argissolo Amarelo distrocoeso em diferentes manejos. Revista Brasileira de Engenharia Agrícola e Ambiental, v.14, p.907-913, 2010.

Pacheco, L. P.; Leandro, W. M.; Machado, P. L. O. A.; Assis, R. L.; Cobucci, T.; Madari, B. E.; Petter, F. A. Produção de fitomassa e acúmulo e liberação de nutrientes por plantas de cobertura na safrinha. Pesquisa Agropecuária Brasileira, v.46, p.17-25, 2011.

Portela, J. C.; Cogo, N. P.; Bagatini, T.; Chagas, J. P.; Portz, G. Restauração da estrutura do solo por sequências culturais implantadas em semeadura direta, e sua relação com a erosão hídrica em distintas condições físicas de superfície. Revista Brasileira de Ciência do Solo, v.34, p.1353-1364, 2010.

Raij, B. van; Cantarella, H.; Quaggio, J. A.; Furlani, A. M. C. Recomendações de calagem e adubação para o Estado de São Paulo. Campinas: Instituto Agronômico de Campinas, 1997. 285p. Boletim Técnico, 100 
Salton, J. C.; Mielniczuk, J.; Bayer, C.; Boeni, M.; Conceição, P. C.; Fabrício, A. C.; Macedo, M. C. M; Broch, D. L. Agregação e estabilidade de agregados do solo em sistemas agropecuários em Mato Grosso do Sul. Revista Brasileira de Ciência do Solo, v.32, p.11-21, 2008.

Santos, G. G.; Marchão, R. L.; Silva, E. M.; Silveira, P. M.; Becquer, T. Qualidade física do solo sob sistemas de integração lavoura-pecuária. Pesquisa Agropecuária Brasileira, v.46, p.1339-1348, 2011.

Santos, G. G.; Silveira, P. M.; Marchão, R. L.; Becquer, T.; Rios, A. W.; Rodrigues, C. Descrição morfológica de perfis de solos da Fazenda Capivara da Embrapa Arroz e Feijão. Santo Antônio de Goiás: Embrapa Arroz e Feijão, 2010. 51p. Documentos, 258
Silva, I. F.; Mielniczuk, J. Ação do sistema radicular de plantas na formação e estabilização de agregados do solo. Revista Brasileira de Ciência do Solo, v.21, p.113-117, 1997.

Silveira, P. M.; Cunha, P. C. R.; Stone, L. F.; Santos, G. G. Atributos químicos de solo cultivado com diferentes culturas de cobertura. Pesquisa Agropecuária Tropical, v.40, p.283-290, 2010.

Siqueira Neto, M.; Piccolo, M. S.; Scopel, E.; Costa Junior, C.; Cerri, C. C.; Bernoux, M. Carbono total e atributos químicos com diferentes usos do solo no cerrado. Acta Scientiarum. Agronomy, v.31, p.709-717, 2009.

Vendrame, P. R. S.; Brito, O. R.; Quantin, C.; Becquer, T. Disponibilidade de cobre, ferro, manganês e zinco em solos sob pastagens na região do cerrado. Pesquisa Agropecuária Brasileira, v.42, p.859-864, 2007. 